\title{
Prediabetes Knowledge, Attitudes, and Practices at an Academic Family Medicine Practice
}

\author{
James W. Keck, MD, MPH, Alisha R. Thomas, MD, MPH, \\ Laura Hieronymus, DNP, MSEd, and Karen L. Roper, PhD
}

Purpose: Lifestyle change programs are an effective but underutilized approach to prevent or delay type 2 diabetes in people with prediabetes. Understanding clinician prediabetes knowledge, attitudes, and practices can inform implementation efforts to increase lifestyle change program referrals.

Methods: We surveyed clinicians at an academic family medicine clinic about their prediabetes knowledge, attitudes, and practices. From the same clinic, we reviewed electronic health records to assess prediabetes screening, diagnosis, and treatment coverage in the cohort of adults seen from 2015 to 2017.

Results: Thirty-one clinicians (69.6\%) completed the survey. Clinicians believed prediabetes was an important health issue $(n=29 ; 93.7 \%)$ and that prediabetes screening $(n=20,64.5 \%)$ and diagnosis $(\mathrm{n}=31,100 \%)$ were important for prediabetes management. About half of the respondents $(\mathrm{n}=14$; 45.2\%) reported familiarity with the National Diabetes Prevention Program (DPP). Electronic chart review included 15,520 adult patients. Most of the 5360 nondiabetic patients meeting US Preventive Services Task Force diabetes screening guidelines $(n=4068 ; 75.9 \%)$ received a hemoglobin A1c test. Of the 1437 patients with an A1c result diagnostic of prediabetes, $729(50.7 \%)$ had the diagnosis in their chart. Prediabetes patients receiving point-of-care A1c testing instead of laboratory testing had 4.7 increased odds ( $95 \%$ CI, 3.5 to 6.4) of metformin prescription. No patients were referred to a DPP.

Conclusions: Clinicians' positive attitudes toward prediabetes screening, moderate knowledge of prediabetes management, and low awareness of DPPs were reflected by high diabetes screening coverage, limited prediabetes diagnosis, and no DPP referrals. We will tailor our implementation strategy to overcome these prediabetes care barriers. (J Am Board Fam Med 2019;32:505-512.)

Keywords: Attitude, Cohort Studies, Life Style, Point-of-Care Systems, Prediabetic State, Primary Health Care, Surveys and Questionnaires, Type 2 Diabetes Mellitus

Prediabetes, a condition of impaired blood glucose regulation, significantly increases the risk of developing type 2 diabetes: up to $11 \%$ of individuals with prediabetes will develop diabetes each year. ${ }^{1}$

This article was externally peer reviewed.

Submitted 17 December 2018; revised 12 February 2019; accepted 17 February 2019.

From the Department of Family \& Community Medicine, University of Kentucky College of Medicine, Lexington (JWK, KLR); Department of Preventive Medicine and Environmental Health, University of Kentucky College of Public Health, Lexington (JWK, ART); Barnstable Brown Diabetes Center, University of Kentucky College of Medicine, Lexington (HL).

Funding: This publication was supported by the National Center for Research Resources and the National Center for Advancing Translational Sciences, National Institutes of Health, through Grant UL1TR001998. The content is solely the responsibility of the authors and does not necessarily represent the official views of the NIH.
Nationally, an estimated 84.1 million American adults ( 1 in 3 ) have prediabetes. ${ }^{2}$ Prediabetes fits in a cascade of care paradigm ${ }^{3}$ with opportunities to identify patients with prediabetes, connect and retain them in care, and meet treatment goals. $\mathrm{Na}$ tional estimates suggest that $46 \%$ of adults are appropriately screened for diabetes. ${ }^{4}$ Of these, $30 \%$

Conflict of interest: none declared.

Corresponding author: James W. Keck, MD MPH, University of Kentucky College of Medicine, Department of Family \& Community Medicine, 2195 Harrodsburg Road, Lexington, KY 40504-3504 (E-mail: James.Keck@uky.edu).

See Related Commentary on Page 457. 
have prediabetes ${ }^{5}$ with only $7 \%$ to $11 \%$ aware of their condition. ${ }^{5,6}$

People with prediabetes can substantially reduce their risk of progression to type 2 diabetes through participation in evidence-based lifestyle change programs. $^{7}$ A multi-center randomized controlled trial showed that intensive lifestyle modification with modest weight loss reduced the risk of progression to type 2 diabetes by $58 \%$ at about 3 years ${ }^{8,9}$ with the protective benefit persisting up to 10 years after lifestyle program completion. ${ }^{1}$ These pivotal outcomes led the Centers for Disease Control and Prevention to establish the National Diabetes Prevention Program (DPP) in 2010. In 2014, the US Community Preventive Services Task Force recommended the approach used by the National DPP as an effective intervention to prevent or delay type 2 diabetes. ${ }^{10}$

Unfortunately, lifestyle change programs, such as DPPs, are underutilized. ${ }^{11}$ States have identified various barriers to DPP scale up and utilization. ${ }^{12}$ From a clinical perspective, attitudes toward prediabetes as a diagnostic construct, ${ }^{13}$ concern for overdiagnosis, ${ }^{14}$ and clinician knowledge of screening guidelines and prediabetes diagnostic criteria ${ }^{15}$ may deter screening and diagnosis of prediabetes. When patients with prediabetes are identified, referrals through primary care have successfully enrolled patients in DPPs ${ }^{16,17}$; however, reported referral coverage has been less than $5 \%$ of eligible patients. ${ }^{11,18}$ Despite strong marketing and implementation efforts, ${ }^{19}$ clinicians often have limited DPP awareness, ${ }^{20}$ may believe patients lack motivation for such programs, ${ }^{15}$ and often lack clear referral processes to such services. ${ }^{12}$ Studies show that when clinicians make patients aware of their prediabetes the likelihood of lifestyle change increases, ${ }^{5,21}$ yet few clinicians routinely refer patients to DPPs. ${ }^{11,20,22,23}$

We designed an implementation study with the objective of increasing DPP referrals in a family medicine clinic. To inform our implementation strategy and establish a baseline of prediabetes practices we assessed clinician knowledge, attitudes, and practices regarding prediabetes and reviewed electronic health records (EHRs) for prediabetes screening, diagnosis and treatment in our patient population.

\section{Methods}

\section{Clinician Survey}

We surveyed clinicians (physicians, resident physicians, and advanced nurse practitioners) at an aca- demic family medicine clinic. We verbally introduced the survey in February 2018 via "All Provider" and resident physician meetings. All clinicians providing direct medical care received an invitation to complete the electronic survey via REDCap (Fort Lauderdale, FL), a secure Health Insurance Portability and Accountability Act (HIPAA)-compliant tool for survey data management. The primary investigator (JWK) was excluded. To develop the survey we conducted a focused literature search and synthesized questions from 3 published surveys of clinician attitudes and knowledge of prediabetes and diabetes. ${ }^{15,24,25}$ Our final survey had 47 total questions grouped by domain: Background Information; Understanding Prediabetes; Beliefs about Prediabetes; Barriers to Management of Prediabetes; Prediabetes management, and; Diabetes Prevention Programs. The survey used Likert scale and multiple-choice questions. Likert scale questions had response options of strongly agree, agree, neither agree or disagree, disagree, and strongly disagree. We conducted descriptive analyses of survey data using SAS software version 9.4 (SAS Institute Inc., Cary, NC) and report counts and proportions. For the analysis, we grouped strongly agree and agree responses and disagree and strongly disagree responses. Respondents received no compensation for survey completion.

\section{Patient Data}

The study clinic uses an Allscripts EHR for clinical documentation. We queried the EHR data warehouse for all adults (age $\geq 18$ years) seen in the clinic within the 3 years before December 1, 2017. The patient data set included deidentified demographic, insurance, and clinical data relevant to prediabetes, including body mass index (BMI), hemoglobin A1c (A1c) values, diabetes, and prediabetes diagnoses based on ICD10 (International Classification of Disease version 10) codes, and metformin prescription. For repeated measures (eg, $\mathrm{BMI}$ and A1c) we used the most recent value. To calculate diabetes screening coverage we applied the diabetes screening guidelines from the US Preventive Services Task Force (USPSTF) and endorsed by the American Academy of Family Physicians, that is, screening overweight or obese adults aged 40 to 70 years. $^{26,27}$ The EHR does not indicate fasting laboratory tests, so we extracted A1c values (point-of-care [POC] and laboratory) because they accurately reflect blood glucose con- 
Table 1. Clinician Knowledge of Prediabetes Diagnosis and Treatment at an Academic Family Medicine Practice

\begin{tabular}{|c|c|c|}
\hline Prediabetes Question & Correct Answer & $\begin{array}{l}\text { Answered Correctly } \\
\qquad(\mathrm{N}=31)\end{array}$ \\
\hline Fasting glucose range indicative of prediabetes & 100 to $125 \mathrm{mg} / \mathrm{dL}^{29}$ & $21(67.7 \%)$ \\
\hline Hemoglobin A1c range indicative of prediabetes & 5.7 to $6.4 \%{ }^{29}$ & $30(96.8 \%)$ \\
\hline $\begin{array}{l}\text { It is recommended that prediabetics lose what } \\
\text { proportion of their starting weight? }\end{array}$ & $5 \%$ to $7 \% 29$ & $10(32.3 \%)$ \\
\hline $\begin{array}{l}\text { How much physical activity per week should be } \\
\text { recommended for patients with prediabetes, } \\
\text { assuming they have no other health issues? }\end{array}$ & $\begin{array}{l}75 \text { minutes vigorous; } \\
150 \text { minutes } \\
\text { moderate }^{29}\end{array}$ & $21(67.7 \%)$ \\
\hline How often should you routinely screen for diabetes? & $\begin{array}{l}\text { Every three } \\
\text { years }\end{array}$ & $12(38.7 \%)$ \\
\hline
\end{tabular}

centrations regardless of fasting. ${ }^{28} \mathrm{We}$ used the American Diabetes Association A1c criteria for prediabetes: an A1c value of 5.7 to $6.4 \%$ in the absence of previously diagnosed diabetes. ${ }^{29} \mathrm{We}$ used Stata version 12.1 (StataCorp, College Station, TX) for descriptive data analysis and report counts, proportions, and odds ratios (ORs) with $95 \%$ confidence intervals $(95 \% \mathrm{CI})$.

\section{Ethics}

This study was approved by the University of Kentucky Institutional Review Board (\#42484).

\section{Results}

\section{Clinician Survey}

Of 46 invited clinicians, 31 (69.6\%) completed the survey. Respondents tended to be female ( $\mathrm{n}=19$; $61.3 \%$ ) and most reported less than 5 years of practice experience $(n=18 ; 58.1 \%)$. Clinicians had varying knowledge of prediabetes diagnostic criteria and screening recommendations (Table 1): 30 $(96.8 \%)$ correctly identified the A1c range diagnostic of prediabetes, and $21(67.7 \%)$ correctly identified the fasting blood glucose range diagnostic of diabetes.

Clinician attitudes toward prediabetes and DPP awareness are found in Table 2. Most $(\mathrm{n}=29$, 93.7\%) believed prediabetes to be a significant public health issue, and many believed screening for prediabetes was important $(\mathrm{n}=20,64.5 \%)$. All clinicians believed that prediabetes diagnosis would increase patient awareness for lifestyle modification and that lifestyle modification is effective to prevent or delay type 2 diabetes $(\mathrm{n}=31,100 \%)$. Fewer clinicians $(\mathrm{n}=$ 14; 45.2\%) reported familiarity with DPPs. Awareness of the DPP referral process $(n=15 ; 48.4 \%)$, organizations offering the DPP ( $\mathrm{n}=13 ; 41.9 \%)$, and insurance coverage of DPPs $(\mathrm{n}=5 ; 16.1 \%)$ was low.

Clinicians reported counseling most patients (75\% to $100 \%)$ with prediabetes on physical activity $(\mathrm{n}=27 ; 87.1 \%)$ and recommending nutritional counseling $(\mathrm{n}=21 ; 67.7 \%)$. Fewer clinicians $(\mathrm{n}=$ $10 ; 32.3 \%$ ) reported prescribing metformin to most patients with prediabetes, and no clinician reported referring most patients to a DPP. Table 3 describes additional clinician-reported prediabetes management practices.

\section{Electronic Chart Review}

We identified 15,250 unique patients aged 18 years or older with at least 1 clinic visit during the study time frame. This cohort had 2463 patients with an ICD10 diagnosis indicative of diabetes. Prediabetes was listed as an ICD10 diagnosis for 2412 patients $(15.8 \%)$ including 561 patients $(3.7 \%)$ with a dual diagnosis of prediabetes and type 2 diabetes. Of the patients with a prediabetes diagnosis, 1379 (58.4\%) had a most recent A1c between 5.7\% and 6.4\% (see Table 4 for additional patient demographic and clinical information). There were 2298 nondiabetic patients with an A1c result in the prediabetes range, and $1089(47.4 \%)$ of these patients had a prediabetes diagnosis (ICD10 code) in their chart. Prediabetes documentation was more likely (OR, 14.9; 95\% CI, 9.9 to 22.3 ) in patients receiving POC A1c testing $(276 / 303)$ than those receiving lab-based testing $(813 / 1,995)$.

There were 5360 patients $(41.9 \%)$ without a diagnosis of diabetes that met USPSTF diabetes screening criteria (age 40 to 70 years and $\mathrm{BMI} \geq 25$ $\mathrm{kg} / \mathrm{m}^{2}$ ). From this cohort of patients, $75.9 \% 4,068$ had a documented A1c result within the previous 3 years, which for $35.3 \% 1,437$ of the patients was 
Table 2. Clinician Prediabetes Attitudes and Diabetes Prevention Program Awareness at an Academic Family Medicine Practice

\begin{tabular}{|c|c|c|c|}
\hline & $\begin{array}{l}\text { Strongly Agree } \\
\text { or Agree }\end{array}$ & $\begin{array}{l}\text { Neither Agree } \\
\text { nor Disagree }\end{array}$ & $\begin{array}{l}\text { Strongly Disagree } \\
\text { or Disagree }\end{array}$ \\
\hline \multicolumn{4}{|l|}{ Prediabetes attitudes } \\
\hline $\begin{array}{l}\text { Prediabetes is a significant } \\
\text { public health issue }\end{array}$ & $29(93.6 \%)$ & $2(6.5 \%)$ & $0(0.0 \%)$ \\
\hline $\begin{array}{l}\text { Most primary care providers } \\
\text { consider screening for } \\
\text { prediabetes to be a high } \\
\text { priority }\end{array}$ & $20(64.5 \%)$ & $5(16.1 \%)$ & $6(19.3 \%)$ \\
\hline $\begin{array}{l}\text { The diagnosis of prediabetes } \\
\text { leads to further } \\
\text { unnecessary investigation/ } \\
\text { testing }\end{array}$ & $1(3.2 \%)$ & $5(16.1 \%)$ & $25(80.6 \%)$ \\
\hline $\begin{array}{l}\text { Diagnosing prediabetes is an } \\
\text { effective way to increase } \\
\text { patient awareness of their } \\
\text { need for lifestyle } \\
\text { modification }\end{array}$ & $31(100.0 \%)$ & $0(0.0 \%)$ & $0(0.0 \%)$ \\
\hline $\begin{array}{l}\text { Evidence supports the } \\
\text { effectiveness of treating } \\
\text { prediabetes with lifestyle } \\
\text { modification }\end{array}$ & $31(100.0 \%)$ & $0(0.0 \%)$ & $0(0.0 \%)$ \\
\hline $\begin{array}{l}\text { Using metformin will } \\
\text { reduce progression to } \\
\text { diabetes }\end{array}$ & $25(80.6 \%)$ & $4(12.9 \%)$ & $2(6.5 \%)$ \\
\hline $\begin{array}{l}\text { I am confident in my ability } \\
\text { to manage prediabetes }\end{array}$ & $27(87.1 \%)$ & $2(6.5 \%)$ & $2(6.5 \%)$ \\
\hline \multicolumn{4}{|l|}{ DPP awareness } \\
\hline $\begin{array}{l}\text { I am familiar with National } \\
\text { DPPs }\end{array}$ & $14(45.2 \%)$ & $7(22.6 \%)$ & $10(32.3 \%)$ \\
\hline $\begin{array}{l}\text { I know how to refer a } \\
\text { patient to a National } \\
\text { DPP }\end{array}$ & $15(48.4 \%)$ & $1(3.2 \%)$ & $15(48.4 \%)$ \\
\hline $\begin{array}{l}\text { I am aware of local } \\
\text { organizations that offer } \\
\text { National DPPs }\end{array}$ & $13(41.9 \%)$ & $3(9.7 \%)$ & $15(48.4 \%)$ \\
\hline $\begin{array}{l}\text { I am aware of insurance } \\
\text { plans that pay for } \\
\text { National DPPs }\end{array}$ & $5(16.1 \%)$ & $4(12.9 \%)$ & $22(71.0 \%)$ \\
\hline $\begin{array}{l}\text { I expect prediabetic patients } \\
\text { who complete a National } \\
\text { DPP will have long-term } \\
\text { changes in their health } \\
\text { behaviors }\end{array}$ & $11(35.5 \%)$ & $13(41.9 \%)$ & $7(22.6 \%)$ \\
\hline $\begin{array}{l}\text { I expect prediabetic patients } \\
\text { who complete a National } \\
\text { DPP will have a reduced } \\
\text { chance of progressing to } \\
\text { diabetes }\end{array}$ & $22(71.0 \%)$ & $6(19.4 \%)$ & $3(9.7 \%)$ \\
\hline $\begin{array}{l}\text { I expect prediabetic patients } \\
\text { who complete a National } \\
\text { DPP will have resolution } \\
\text { of their prediabetes }\end{array}$ & $5(16.1 \%)$ & $18(58.1 \%)$ & $8(25.8 \%)$ \\
\hline
\end{tabular}

DPP, National Diabetes Prevention Program.

diagnostic of prediabetes. Half of these patients ( $\mathrm{n}=729 ; 50.7 \%$ ) with an A1c value diagnostic of prediabetes had the diagnosis (ICD10 code) in their EHR. Table 5 summarizes the cascade of predia- betes screening, diagnosis, and treatment in the cohort.

Metformin prescription was more likely (OR, $10.7 ; 95 \%$ CI, 6.9 to 16.5 ) in patients with docu- 
Table 3. Clinician-Reported Frequency of Prediabetes Care Practices at an Academic Family Medicine Practice

\begin{tabular}{|c|c|c|c|}
\hline \multirow[b]{2}{*}{ Prediabetes Care Practice } & \multicolumn{3}{|c|}{$\begin{array}{c}\text { For What Proportion* of Your Prediabetic Patients Do you } \\
\text { Perform the Following Management Practices... }\end{array}$} \\
\hline & None & Some & Most \\
\hline Discuss metformin as a treatment option & $0(0.0 \%)$ & $14(45.2 \%)$ & $17(54.8 \%)$ \\
\hline Prescribe metformin & $2(6.5 \%)$ & $19(61.3 \%)$ & $10(32.3 \%)$ \\
\hline $\begin{array}{l}\text { Recommend physical activity targets supported by } \\
\text { national guidelines }\end{array}$ & $0(0.0 \%)$ & $4(12.9 \%)$ & $27(87.1 \%)$ \\
\hline $\begin{array}{l}\text { Have patient set a weight loss goal of } 5 \% \text { to } 7 \% \\
\text { of their current weight }\end{array}$ & $4(12.9 \%)$ & $16(51.6 \%)$ & $11(35.5 \%)$ \\
\hline Recommend nutritional counseling & $0(0.0 \%)$ & $10(32.3 \%)$ & $21(67.7 \%)$ \\
\hline Create a behavioral contract & $25(80.7 \%)$ & $6(19.4 \%)$ & $0(0.0 \%)$ \\
\hline Provide pamphlets or other written resources & $7(22.6 \%)$ & $18(58.1 \%)$ & $6(19.4 \%)$ \\
\hline Offer referral to a CDC-recognized National DPP & $10(32.3 \%)$ & $21(67.7 \%)$ & $0(0.0 \%)$ \\
\hline
\end{tabular}

CDC, Centers for Disease Control and Prevention; DPP, Diabetes Prevention Program.

*Respondents selected between $0 \%, 25 \%, 50 \%, 75 \%$, and $100 \%$.

"None" indicates $0 \%$; "Some" includes $25 \%$ and $50 \%$; "Most" includes $75 \%$ and $100 \%$.

mented prediabetes $(194 / 1,089)$ than patients with undocumented prediabetes $(24 / 1,209)$ and was more likely (OR, 4.7 ; $95 \%$ CI, 3.5 to 6.4 ) in pre- diabetes patients with POC A1c testing (79/303) than laboratory A1c testing $(\mathrm{n}=139 / 1,995)$. No patients were referred to a DPP.

Table 4. Demographic and Clinical Characteristics of Adult Patients with and without Prediabetes Diagnosis at an Academic Family Medicine Practice, 2014 to 2017

\begin{tabular}{|c|c|c|c|c|}
\hline & \multicolumn{2}{|c|}{ All Patients } & \multicolumn{2}{|c|}{ Prediabetes Diagnosis* } \\
\hline & $\mathrm{N}$ & $\%$ & $\mathrm{~N}$ & $\%$ \\
\hline & 15,250 & 100 & 2,412 & $15.8 \%$ \\
\hline \multicolumn{5}{|l|}{ Demographic } \\
\hline Age, years (mean, SD) & 49.3 & 16.4 & 58.2 & 13.3 \\
\hline Female & 8,606 & $56.4 \%$ & 1,255 & $52.0 \%$ \\
\hline \multicolumn{5}{|l|}{ Race } \\
\hline White & 11,967 & $78.5 \%$ & 1,790 & $74.2 \%$ \\
\hline Black/African American & 2,474 & $16.2 \%$ & 517 & $21.4 \%$ \\
\hline Asian & 566 & $3.7 \%$ & 76 & $3.2 \%$ \\
\hline AI/AN, Hawaiian, PI & 79 & $0.5 \%$ & 15 & $0.6 \%$ \\
\hline Unreported & 164 & $1.1 \%$ & 14 & $0.6 \%$ \\
\hline \multicolumn{5}{|l|}{ Health insurance } \\
\hline Private & 8,145 & $53.4 \%$ & 1,109 & $46.0 \%$ \\
\hline Medicare & 3,049 & $20.0 \%$ & 780 & $32.3 \%$ \\
\hline Medicaid & 3,011 & $19.7 \%$ & 399 & $16.5 \%$ \\
\hline Tricare & 291 & $1.9 \%$ & 30 & $1.2 \%$ \\
\hline Financial assistance & 164 & $1.1 \%$ & 25 & $1.0 \%$ \\
\hline None & 590 & $3.9 \%$ & 69 & $2.9 \%$ \\
\hline \multicolumn{5}{|l|}{ Clinical characteristics } \\
\hline $\mathrm{BMI} \geq 25 \mathrm{~kg} / \mathrm{m} 2$ & 11,454 & $75.1 \%$ & 2,122 & $88.0 \%$ \\
\hline Hemoglobin Alc test & 10,095 & $66.2 \%$ & 2,360 & $97.8 \%$ \\
\hline Diabetes diagnosis $^{\dagger}$ & 2,463 & $16.2 \%$ & 561 & $23.3 \%$ \\
\hline
\end{tabular}

AI/AN, American Indian/Alaska Native; BMI, body mass index; PI, Pacific Islander; SD, standard deviation.

${ }^{*}$ Prediabetes diagnosis defined as documented International Classification of Disease version 10 (ICD10) code R73.03 in patient chart. †Diabetes diagnosis determined by ICD10 code in patient chart. For patients with prediabetes code this indicates a dual diagnostic codes. 
Table 5. Prediabetes Care Cascade: Screening, Diagnosis, and Treatment Coverage of Adult Patients at an Academic Family Medicine Practice, 2014 to $2017(\mathrm{~N}=15,250)$

\begin{tabular}{llrr}
\hline Prediabetes Care Cascade & \multicolumn{1}{c}{ Criteria } & $\mathrm{n}$ & $\%$ \\
\hline USPSTF diabetes screening eligible & Nondiabetic patient & 12,787 & $83.8 \%$ \\
& Age 40 to 70 years + BMI $\geq 25 \mathrm{~kg} / \mathrm{m}^{2}$ & 5,360 & $41.9 \%$ \\
Screened & Hemoglobin A1c within 3 years & 4,068 & $75.9 \%$ \\
Prediabetes diagnosed & Hemoglobin A1c of 5.7 to 6.4\% & 1,437 & $35.3 \%$ \\
Prediabetes documented & Prediabetes ICD10 code & 729 & $50.7 \%$ \\
Prediabetes treatment & Metformin prescribed & 149 & $20.4 \%$ \\
& DPP referral & 0 & $0.0 \%$ \\
\hline
\end{tabular}

BMI, body mass index; DPP, Diabetes Prevention Program; ICD10, International Classification of Diseases, version 10; USPSTF, United States Preventive Services Task Force.

The sample size for each row serves as the denominator for the subsequent row.

\section{Discussion}

We describe clinician-reported prediabetes knowledge, attitudes, and practices alongside an EHR review of prediabetes screening and management at a large academic family medicine clinic. Clinicians believed prediabetes was an important health issue and had moderate knowledge of prediabetes screening, diagnosis, and treatment guidelines, but limited familiarity with DPPs. EHR data showed consistent screening for prediabetes/diabetes per USPSTF guidelines; however, diagnosis and treatment of prediabetes were less consistent.

Our survey respondents had broadly favorable attitudes toward prediabetes, recognizing its importance as a health issue, the benefits of screening, and the effectiveness of treatment with lifestyle change and/or metformin. A 2015 survey of practicing primary care clinicians in the Mid-Atlantic region had similar findings ${ }^{15}$; however, a 2016 national survey of primary care physicians' attitudes revealed mixed opinions about prediabetes. ${ }^{13}$ One possible explanation for differing attitudes is increasing clinician awareness of prediabetes from ongoing marketing efforts by a variety of groups, such as the Prevent Diabetes STAT campaign supported by the US Centers for Disease Control and Prevention and the American Medical Association. ${ }^{30}$

Clinicians knew more about prediabetes screening and diagnosis than treatment. Our respondents' limited awareness and knowledge of DPPs was unexpected given the colocation of a DPP in the same office building as the family medicine practice and the presence of a second DPP at the local health department. Our respondents' DPP awareness was similar to that reported in the 2016 national survey of primary care physicians..$^{20}$ Low DPP awareness may be due to the relatively recent rollout of the National DPP and scale-up of organizations offering the DPP. Community organizations or local health departments may host DPPs, and clinicians may have limited awareness of community-based patient resources. $^{31}$

Favorable attitudes toward screening and diagnosing prediabetes likely contributed to the observed high diabetes screening coverage (76\%) in our clinic, which exceeds national diabetes screening coverage $(46 \%){ }^{4}$ Less consistent was the application of the ICD10 prediabetes diagnostic code-only $51 \%$ of patients meeting prediabetes diagnostic criteria had the diagnosis in the EHR. There are no comparative data on prediabetes documentation published since the widespread adoption of ICD10 medical codes. Two studies during the ICD9 era from a large integrated health care system found that $13 \%$ of patients with laboratory results indicative of prediabetes had the diagnosis documented in the EHR. ${ }^{11,32}$ Another study using $2012 \mathrm{Na}$ tional Ambulatory Medical Care Survey data found that too few patients with an A1c indicative of prediabetes received the diagnosis for a reliable documentation estimate $(0.92 \%){ }^{33}$ One explanation for the gap between diagnosis and documentation is that our EHR query was restricted to the ICD10 prediabetes code. We did not include less specific ICD9 codes such as "impaired fasting glucose" and "hyperglycemia" which historically were used for patients with prediabetes ${ }^{18}$ and may continue to be used by some clinicians. The delayed availability of lab-based results may also contribute to missed prediabetes documentation as suggested 
by better prediabetes documentation in patients receiving POC A1c testing.

Clinicians were optimistic in their self-reported prediabetes management behaviors: a third reported routinely (75\% to $100 \%$ of the time) and over half reported regularly ( $25 \%$ to $50 \%$ of the time) prescribing metformin for patients with prediabetes. Although clinicians prescribed less metformin than they perceived, metformin prescription for prediabetes was more common in our clinic than reported in other settings. ${ }^{11,34,35}$ The availability of POC A1c testing in our clinic may have facilitated prediabetes diagnosis and treatment, as patients receiving POC testing were more likely to receive metformin. POC testing in prediabetes management is not well studied; however, substantial evidence supports the benefits of POC testing for diabetes management ${ }^{36}$ and limited evidence suggests it helps identify patients with prediabetes. ${ }^{37}$ Promoting POC testing may be a relatively simple strategy to improve prediabetes screening, diagnosis, and treatment.

Most clinicians reported routinely counseling prediabetes patients on physical activity and weight loss; we were unable to extract chart documentation to assess counseling frequency. Many clinicians reported referring patients to a DPP. About two thirds of clinicians indicated that they referred $25 \%$ to $50 \%$ of their patients with prediabetes which is similar to the $23 \%$ of primary care clinicians who reported making a DPP referral in the 2016 national survey. ${ }^{20}$ At the time of the EHR review, an electronic DPP referral did not exist and there was no process for referring patients to the 2 local DPPs. Some clinicians may have discussed DPPs with patients: however, this was not captured as part of our EHR review. Clinicianreported referral behaviors may also suffer from desirability bias; similar discordance was seen in a study linking clinician self-reported prediabetes management practices with EHR documentation. ${ }^{22}$

We recognize limitations to our study. The survey responses from our sample of clinicians at a single academic family medicine clinic may not generalize to other settings; however, the higher response rate minimized nonresponse bias and response patterns aligned with those reported from 2 recent surveys of primary care physicians. ${ }^{13,15}$ We may have underestimated the proportion of our clinical cohort with prediabetes due to the EHR inability to identify fasting blood glucose results; however, almost all (97.8\%) of the patients with documented prediabetes had an Alc in the EHR.
Our clinician survey and EHR review are part of a broader implementation study; hence our study design emphasized collecting data useful for implementation planning. We will tailor implementation strategies to overcome identified barriers to DPP referral, namely the lack of an EHR referral process, the underdocumentation of prediabetes, and the limited DPP awareness reported by clinicians, while reinforcing prediabetes care assets, such as clinicians' positive prediabetes attitudes and the use of POC A1c testing.

We thank Roberto Cardarelli for his mentorship and critical review of the manuscript. We thank Dhishankar Bhattacharya for extracting and formatting the clinical data.

To see this article online, please go to: http://jabfm.org/content/ 32/4/505.full.

\section{References}

1. Diabetes Prevention Program Research Group. 10year follow-up of diabetes incidence and weight loss in the Diabetes Prevention Program Outcomes Study. Lancet 2009;374:1677-86.

2. National diabetes statistics report: Estimates of diabetes and its burden in the United States, 2014. Atlanta, GA: Centers for Disease Control and Prevention; 2017.

3. Ali MK, Bullard KM, Gregg EW, et al. A cascade of care for diabetes in the United States: Visualizing the gaps. Ann Intern Med 2014;161:681-9.

4. Kiefer MM, Silverman JB, Young BA, et al. National patterns in diabetes screening: Data from the National Health and Nutrition Examination Survey (NHANES) 2005-2012. J Gen Intern Med 2015;30:612-8.

5. Geiss LS, James C, Gregg EW, et al. Diabetes risk reduction behaviors among U.S. adults with prediabetes. Am J Prev Med 2010;38:403-9.

6. Centers for Disease Control and Prevention. Awareness of prediabetes-United States, 2005-2010. MMWR Morb Mortal Wkly Rep 2013;62:209-12.

7. Hemmingsen B, Gimenez-Perez G, Mauricio D, et al. Diet, physical activity or both for prevention or delay of type 2 diabetes mellitus and its associated complications in people at increased risk of developing type 2 diabetes mellitus. Cochrane Database Syst Rev 2017;2017(12).

8. Knowler WC, Barrett-Connor E, Fowler SE, et al. Reduction in the incidence of type 2 diabetes with lifestyle intervention or metformin. $\mathrm{N}$ Engl J Med 2002;346:393-403.

9. Tuomilehto J, Lindström J, Eriksson JG, et al. Prevention of type 2 diabetes mellitus by changes in lifestyle among subjects with impaired glucose tolerance. N Engl J Med 2001;344:1343-50.

10. Pronk NP, Remington PL. Combined diet and physical activity promotion programs for prevention 
of diabetes: Community preventive services task force recommendation statement. Ann Intern Med 2015;163:465-8.

11. Schmittdiel JA, Adams SR, Segal J, et al. Novel use and utility of integrated electronic health records to assess rates of prediabetes recognition and treatment: brief report from an integrated electronic health records pilot study. Diabetes Care 2014;37:565-8.

12. Mensa-Wilmot Y, Bowen SA, Rutledge S, et al. Early results of States' efforts to support, scale, and sustain the National Diabetes Prevention Program. Prev Chronic Dis 2017;14:E130.

13. Mainous AG 3rd, Tanner RJ, Scuderi CB, et al. Prediabetes screening and treatment in diabetes prevention: The impact of physician attitudes. J Am Board Fam Med 2016;29:663-71.

14. Yudkin JS, Montori VM. The epidemic of pre-diabetes: The medicine and the politics. BMJ 2014;349:g4485.

15. Tseng E, Greer RC, O'Rourke P, et al. Survey of primary care providers' knowledge of screening for, diagnosing and managing prediabetes. J Gen Intern Med 2017;32:1172-8.

16. Vojta D, Koehler TB, Longjohn M, et al. A coordinated national model for diabetes prevention: Linking health systems to an evidence-based community program. Am J Prev Med 2013;44(4 Suppl 4):S301-S306.

17. Chambers EC, Wylie-Rosett J, Blank AE, et al. Increasing referrals to a YMCA-based diabetes prevention program: Effects of electronic referral system modification and provider education in federally qualified health centers. Prev Chronic Dis 2015;12:E189.

18. Cloney TA, Galer-Unti RA, Barkley WM. Provider practices in prediabetes intervention and diabetes prevention: application of evidence-based research in the medical office setting. J Prim Care Community Health 2011;2:187-91.

19. Gallivan J, Greenberg R, Brown C. The National Diabetes Education Program evaluation framework: How to design an evaluation of a multifaceted public health education program. Prev Chronic Dis 2008; 5(4):A134.

20. Nhim K, Khan T, Gruss SM, et al. Primary care providers' prediabetes screening, testing, and referral behaviors. Am J Prev Med 2018;55:e39-e47.

21. Gopalan A, Lorincz IS, Wirtalla C, Marcus SC, Long JA. Awareness of prediabetes and engagement in diabetes risk-reducing behaviors. Am J Prev Med 2015;49:512-9.

22. Mehta S, Mocarski M, Wisniewski T, et al. Primary care physicians' utilization of type 2 diabetes screening guidelines and referrals to behavioral interventions: A survey-linked retrospective study. BMJ Open Diabetes Res Care 2017;5(1).

23. Hafez D, Nelson DB, Martin EG, Cohen AJ, Northway R, Kullgren JT. Understanding type 2 diabetes mellitus screening practices among primary care physicians: a qualitative chart-stimulated recall study. BMC Fam Pract 2017;18:50.
24. Fearn-Smith JD, Evans PH, Harding G, et al. Attitudes of GPs to the diagnosis and management of impaired glucose tolerance: The practitioners' attitudes to hyperglycaemia (PAtH) questionnaire. Prim Care Diabetes 2007;1:35-41.

25. Helmink JHM, Kremers SPJ, van Boekel LC, et al. Factors determining the motivation of primary health care professionals to implement and continue the "Beweegkuur" lifestyle intervention programme. J Eval Clin Pract 2012;18:682-8.

26. U.S. Preventive Services Task Force. Final recommendation statement: Abnormal blood glucose and type 2 diabetes mellitus: Screening. November 2, 2018. Available from: https://www.uspreventiveservicestaskforce.org/Page/Document/Recommendation StatementFinal/screening-for-abnormal-blood-glucoseand-type-2-diabetes.

27. American Academy of Family Physicians. Clinical preventive service recommendation: Abnormal blood glucose and type 2 diabetes mellitus, adults. 2015. Available from: https://www.aafp.org/patient-care/clinicalrecommendations/all/diabetes-screening.html.

28. Sacks DB, Arnold M, Bakris GL, et al. Guidelines and recommendations for laboratory analysis in the diagnosis and management of diabetes mellitus. Diabetes Care 2011;34:e61-e99.

29. American Diabetes Association. Standards of medical care in diabetes-2017 abridged for primary care providers. Clin Diabetes 2017 Jan;35:5-26.

30. American Medical Association. Prevent diabetes STAT. Available from: https://assets.ama-assn.org/ sub/prevent-diabetes-stat/. Published 2018. Accessed October 23, 2018.

31. Craven MA, Kates N, Raso P. Assessment of family physicians' knowledge of social and community services. Can Fam Physician 1990;36:443-7.

32. Marshall C, Adams S, Dyer W, et al. Opportunities to reduce diabetes risk in women of reproductive age: Assessment and treatment of prediabetes within a large integrated delivery system. Womens Health Issues 2017;27:666-72.

33. Mainous AG 3rd, Tanner RJ, Baker R. Prediabetes diagnosis and treatment in primary care. J Am Board Fam Med 2016;29:283-5.

34. Moin T, Li J, Duru OK, et al. Metformin prescription for insured adults with prediabetes from 2010 to 2012: A retrospective cohort study. Ann Intern Med 2015;162:542-8.

35. Wu J, Ward E, Threatt T, Lu ZK. Metformin prescribing in low-income and insured patients with prediabetes. J Am Pharm Assoc 2017;57:483-7.

36. Schnell O, Crocker JB, Weng J. Impact of HbA1c testing at point of care on diabetes management. J Diabetes Sci Technol 2017;11:611-7.

37. Whitley HP, Hanson C, Parton JM. Systematic diabetes screening using point-of-care HbA1c testing facilitates identification of prediabetes. Ann Fam Med 2017;15:162-4. 